\title{
Caring for the caregivers: Innovative program for oncology nurses
}

\author{
By Margaret I. Fitch, Yvette Matyas and Marny Robinette
}

\section{Abstract}

An innovative program, Care for the Professional Caregiver, was designed to provide staff nurses in a cancer program with the opportunity to learn about coping with stress in their practice. The program was evaluated using quantitative and qualitative methods. The findings clearly describe the benefits of the program on both a short- and long-term basis. The value of connecting with other cancer nurses, supporting each other, and sharing stories about their work life experiences resulted in benefits to the nurse as an individual, as a team member, and as a professional practitioner. The program achieved its aims and is recommended for ongoing implementation.

\section{Introduction and background}

Despite advances in cancer treatment and decreases in mortality rates, a cancer diagnosis is still seen by many as a death sentence (Loney, 1998). The majority of those diagnosed with the disease have thoughts about dying and their own mortality (Fitch \& Steele, 2003). They experience feelings of powerlessness and loss of control over their lives. The $50 \%$ who do succumb to the disease have to cope with anticipatory grief and planning for end-of-life care.

Oncology nurses caring for individuals with cancer confront death regularly and are witness to the suffering it brings. One of the goals of oncology nursing is assisting individuals, patients and family members to cope with the psychosocial issues related to their cancer experience. This is accomplished through a therapeutic use of self and building an interpersonal relationship with the respective individuals. Nursing has been described as "interpersonal work," ongoing in nature, and enacted through a personal relationship with individual patients within the context of a wider organizational and social context (Corner, 2002). Nurses' conscious and unconscious feelings are part of this relationship and enter into exchanges with patients (Lancely, 2001). By becoming part of the dying patient's world, the nurse shares the burden of suffering through caring, empathy and compassion (King \& Jordan-Welch, 2003). They also share burdens of grief and bereavement when patients die (Feldstein \& Gemma, 1995; Saunders \& Valente, 1994).

Oncology nursing has long been recognized as an emotionally demanding specialty (Newlin \& Wellisch, 1978; Wilkinson, 1994). The demands have been described as sources of stress (Kushnir, Rabin, \& Azulai, 1997; Vachon, 1986), contributing factors to burnout (Lewis, 1999; McElroy, 1982; Yasko, 1983) and difficulties encountered in practice (Cohen \& Sarter, 1992; Lev, 1994). Examples of the demands include death of a favourite patient, multiple losses and exposure to death, caring for patients receiving unpleasant treatments, conflicts between doctor and nurses about goals of care, high caseloads, and difficult relationships with co-workers.

During the past decade in Canada, significant changes have occurred in the cancer care delivery system: reduced financial resources, new organizational models, health care reform, restructuring and mergers. Trends toward reducing inpatient hospital stays, providing more care on an ambulatory or community basis, and increased complexity in cancer treatment protocols have resulted in increased patient acuity. Cancer nurses describe changes in their work environments, workloads, reporting relationships, numbers of coworkers, available resources and professional leadership (Bakker, Fitch, Green, Butler, \& Olson, in press). For many, their job satisfaction has decreased and they worry about their capacity to provide safe or quality care (Lamkin, Rosiak, Buerhaus, Mallory \& Williams, 2002; Lovern, 2001). These organizational variables are cited as major sources of stress for nurses (Cohen, Haberman, Steeves, \& Deatrick, 1994; Corner, 2002).

Despite all the changes, cancer nurses remain deeply committed to their patients and highly motivated to provide good care (Bakker et al., in press). Many strive to meet their patients' needs, but at some cost to themselves. Larson (1992) wrote about the constant struggle to find a way to become emotionally involved with dying patients while also taking care of oneself. Nurses cannot be present in supporting dying patients without first recognizing and meeting their own needs. The metaphors nurses use to describe their work are often ones of battle, fighting and combat (Cohen \& Sarter, 1992; Kushnir, Rabin, \& Azulai, 1997). Many perceive the multiple daily challenges in the present cancer system as hindering their "doing real nursing work" and they feel a resulting sense of frustration and despair (Bakker et al., in press).

When distress in care providers remains unchecked, there can be significant impact on the individual and on patient care. Excessive and continued occupational stress in cancer nursing can be associated with a variety of emotions, including anxiety and depression, job dissatisfaction and reduced quality of life (Kushnir, Rabin, \& Azulai, 1997). Stress has been implicated in a variety of diseases (e.g., cardiovascular, diabetes, etc.) and behavioural problems at work (e.g., absenteeism) (Lancely, 2001). Eventual outcomes will include poor work performance, turnover and leaving the profession (Vachon, 1986).

A challenge for administrators and managers in cancer programs is to find ways of effectively and meaningfully supporting nursing staff in practice environments that have little likelihood of changing soon. Finances will continue to be tight, patient loads will continue to be high, and organizational processes will continue to be complex. Oncology nurses need to find ways to balance their work life and personal life, and ways to cope with the ongoing demands of the specialty practice. This paper describes the approach one cancer program adopted to support their nursing staff.

\section{Innovative program for nursing staff}

At our cancer centre, discussions about how to meet the challenge of supporting oncology nurses led to the creation of a program entitled Caring for the Professional Caregiver. The initiative was a day-long retreat workshop for nursing staff without supervisory or management staff present. The day was a paid working day and was held in the home-like environment of Wellspring, a cancer patient support organization near the cancer centre. The initiative was a partnership between the cancer centre and Wellspring. The expertise Wellspring staff possess in running support groups for cancer patients formed the basis for designing the program for staff.

Margaret I. Fitch, RN, PhD, is Director of the Psychosocial and Behavioural Research Unit at Toronto Sunnybrook Regional Cancer Centre, Toronto, Ontario.marg.fitch@sunnybrook.ca

Yvette Matyas, BA(Psych), MN, is Director, Operations at Toronto Sunnybrook Regional Cancer Centre, Toronto, Ontario.

Marny Robinette, BA, is Manager of Wellspring at Toronto Sunnybrook Regional Cancer Centre, Toronto, Ontario. 
The day was organized to accomplish the following goals:

- help nurses find balance in their work lives and their personal lives, and

- to assist nurses in coping with the ongoing demands of their specialty practice.

The actual agenda is presented in Table One. The program was based on principles of adult education with a variety of teaching and learning methods incorporated into the sessions. The day itself was a balance of activities.

1. Educational content was presented regarding vicarious trauma and loss and the impact, both emotionally and physically, they have on health care professionals. Over and above the actual content on the topics, it was anticipated this information would help nurses acknowledge the reality of these phenomena in their practice lives and the normalcy of feeling their impact. It was also an attempt to provide words and concepts for nurses to be able to talk about their experiences with suffering and loss of patients.

2. An opportunity was made to have nurses share stories about their personal experiences with suffering and loss in a supportive environment. They talked about their daily practice lives and the types of situations they faced with patients and families. Inpatient and outpatient nursing staff talked together in small groups of between six to eight individuals. Each group had a facilitator trained for this type of group work.

3. Educational content was shared about the importance of self-care and about strategies for personal self-care at home and within the workplace. This session was anticipated to enlarge nurses' knowledge base regarding specific strategies that they could use.

4. Demonstrations of relaxation techniques (e.g., visualization, full body relaxation, yoga, massage) were provided together with opportunities for the participants to experience and to practice each technique. The participants could learn about how to perform a particular technique as well as experience its effect. Even if they did not elect to use it themselves, they could tell other colleagues or patients about it in the future.

The same program was run several times to allow as many staff to attend as possible. A second series was run using a similar format, but focusing on different relaxation exercises. The individuals who facilitated during the day-long retreat had professional expertise in the reflective content areas and training in support group facilitation. All were part of the cadre of Wellspring program facilitators or leaders.

The day-long retreat was advertised with flyers posted on the units. Staff members indicated to their managers which time they would go. Each retreat had 20 to 24 nurses with a mixture of inpatient (medical/radiation and surgical) and outpatient staff. Many individuals attended on two occasions since the program ran over two years.

\section{Evaluation methods}

Two approaches were used to evaluate the outcomes of the program. At the end of the retreat day, all participants were asked to complete an evaluation form to assess short-term outcomes and impressions about the program. The items on the evaluation form elicited feedback about all aspects of the day's activities and learning in relation to each of the objectives. These forms were collected by Wellspring volunteers and summarized for each day. This feedback was used to make small adjustments to the program in subsequent sessions.

To explore the long-term outcomes, in-depth interviews were conducted one year after the program with 21 nurses who attended the retreat workshop. An individualized letter of invitation was sent to each nurse who had attended the caregiver program. The letter explained the purpose of the interviews and invited participation. A follow-up telephone contact was made by the research assistant to determine interest in participating. For those who were interested in participating, the interview was conducted by the research assistant at a time and place convenient for the staff nurse.

The interview guide was developed by the authors for this evaluation and used a semi-structured format. Questions elicited the staff nurses' recollection of what occurred during the retreat, perspectives about the retreat, and any differences that were noticed after attending the retreat in self-care activities, interactions with coworkers, or interactions with patients and family members. Interviewees were also asked what recommendations they would make about the retreat program for the future.

All interviews were audio-recorded and later transcribed verbatim by the research assistant. Any identifying features were removed from the transcripts before the text was seen by the principal investigator. Given the principal investigator was also head of the nursing division, she did not listen to the actual tapes so as to avoid the risk of recognizing the voices of the staff nurses who participated in the interviews.

The analysis of the transcripts focused on content and theme analysis (Silverman, 2000). The principal investigator provided the leadership for this stage of the work. Interview transcripts were reviewed in their entirety and a broad coding scheme was designed for the content. The interviews were then coded by one team member (MF) according to the coding scheme. The coding scheme did not undergo revision during this stage of the process. The coded

Table One. Our program: Care for the Professional Caregiver

Agenda Outline for Retreat

\begin{tabular}{|l|l|l|}
\hline Goals & Version 1 & Version 2 \\
\hline $\begin{array}{l}\text { Knowledge } \\
\text { (learning) } \\
\text { (new content) } \\
\text { morning }\end{array}$ & $\begin{array}{l}\bullet \text { Vicarious trauma/loss } \\
\bullet \text { Group discussion re. personal } \\
\text { experiences in work environment } \\
\bullet \text { Strategies for self-care }\end{array}$ & $\begin{array}{l}\bullet \text { Vicarious trauma/loss } \\
\text { Role of personality } \\
\bullet \text { Group discussion re. personal } \\
\text { experiences in work environment } \\
\text { Value of self knowledge } \\
\bullet \text { Strategies for self care }\end{array}$ \\
\hline $\begin{array}{l}\text { Skills (practice techniques } \\
\text { for self care) } \\
\text { afternoon }\end{array}$ & $\begin{array}{l}\bullet \text { Visualization and relaxation } \\
\bullet \text { Body/mind exercises } \\
\text { Y Yoga }\end{array}$ & $\begin{array}{l}\bullet \text { Journaling } \\
\text { Visualization/relaxation } \\
\bullet \text { Mind-body exercises }\end{array}$ \\
\hline $\begin{array}{l}\text { Networking (opportunity } \\
\text { to meet other cancer nurses) }\end{array}$ & $\begin{array}{l}\bullet \text { Home-like environment } \\
\bullet \text { Food catered } \\
\bullet \text { Time built into agenda for informal chatting }\end{array}$ & $\begin{array}{l}\bullet \text { Home-like environment } \\
\bullet \text { Food catered }\end{array}$ \\
\hline
\end{tabular}


material was then reviewed and summarized for each category to reflect the range of ideas shared by the participants, and themes were generated.

\section{Evaluation results}

\section{Part I: Quantitative findings}

A total of 103 evaluation forms were collected at the end of eight of the day-long sessions. The majority of the submissions came from nurses who had been at our institution for more than five years (see Table Two).

The respondents identified learning relaxation techniques most frequently as what they expected to learn from the session. Eighty per cent $(n=83)$ listed this item as the primary reason they came to the session. The next most frequently identified expectation was "learning about emotional care of myself" with $36 \%(\mathrm{n}=37)$ of the respondents listing this type of item. Only 11 individuals (10.6\%) listed networking or interfacing with other cancer nurses as a goal for attendance at the session. Without exception, the respondents indicated the session had met their expectations.

The respondents were asked to identify the primary stressors in their daily practice lives, or the types of factors that influenced how they felt about and coped with their role as an oncology nurse. A summary of their responses is presented in Table Three. The descriptions provided clear validation that these nurses were dealing with tremendous stress on a daily basis and initiatives such as the retreat program were needed to support them. These stresses were often the central focus of the stories nurses shared during the group discussions at the retreat.

All respondents rated the retreat session as helpful $(26 \%)$ or extremely helpful (79\%) and were satisfied with the program; 98\% indicated they would recommend it to colleagues. The major criticisms of the program were that it was too short. Eighty-five per cent of the respondents indicated wanting more time with various aspects of the program. The types of written comments added to the form included the following:

- Thank you. It was wonderful!

- Meaningful, realistic, enjoyable. Would like this for staff on a regular basis.

- Very informative and beneficial.

- Increased my awareness. Gave me good insight.

- Lets me know that everyone is going through what I am - the same experiences.

- A very good opportunity to rejuvenate myself.

- It was a peaceful and relaxing day away from the stresses at work. All respondents said they would attend the program again. Eightyone per cent indicated they would do so on their own time (i.e. outside of work time) and more than half (59\%) indicated they would like to attend a program like this annually. The remainder wanted the program to be offered more often.

Table Two. Selected demographics of cancer nurse participants

\begin{tabular}{|l|l|l|}
\hline Item & $\begin{array}{l}\text { Quantitative } \\
\text { Evaluation }(\mathrm{N}=103)\end{array}$ & $\begin{array}{l}\text { Qualitative } \\
\text { Evaluation }(\mathrm{N}=21)\end{array}$ \\
\hline Inpatient Staff & 76 & 12 \\
\hline Outpatient Staff & 27 & 9 \\
\hline Time at Institution & & \\
\hline$<6$ months & 5 & - \\
\hline $6-12$ months & 12 & - \\
\hline $12.1-24$ months & 11 & 2 \\
\hline $\begin{array}{l}24.1 \text { months }- \\
5 \text { years }\end{array}$ & 10 & 3 \\
\hline$>5$ years & 65 & 16 \\
\hline
\end{tabular}

Finally, the respondents offered very few recommendations for improving the program. Slight alterations in the timing for specific topics and the idea of including bereavement as a topic were offered. Most of the comments reflected a desire for the program to be offered more often, for all staff nurses to have the opportunity to attend, to expand the sessions to other staff members, and to have similar group discussions with managers.

\section{Part II: Qualitative findings}

The interviews with nurses one year following their attendance at the professional caregiver program lasted between 20 and 60 minutes. Overall, the nurses who were interviewed were not able to recall specific details about the information that was offered, but they had vivid memories of the day. They described their feelings, pictures in their minds about the day, their sense of the sessions, the people and their stories, and talked about the sharing that had occurred. They recalled taking home key messages or ideas about the need for balance in their lives and the realization that others were experiencing the same issues they were experiencing. Overall, the nurses talked about how "cared for" they had felt. The fact the organization had paid for them to go to the session spoke volumes to them about how much they were valued by the agency. They also very clearly described the nature of the stressful events in their working day (Table Three).

This sense that their organization cared for them and about helping them deal with the stressful work environment was embodied in statements such as the following:

Just one day out of work and we relax. And we get paid. They're good about money... they pay you and you look after yourself. And it feels, it feels like you are somebody. You know, you are not just a caregiver... there is somebody caring about you as a caregiver. And they give you that day to be up and gone and take care of yourself. That was excellent. (1)

\section{Table Three. What is stressful} in the daily life of an oncology nurse?

- Lack of equipment

- Chaos in day-to-day environment

- Not enough nursing staff for the amount of work to be done

- Heavy workload/many demands

- Lack of support and understanding from managers and administrators

- Not feeling appreciated for what we do

- Physicians who will not listen to us

- Lack of teamwork

- Not able to vent or show feelings safely at work

- Patients are very ill

- Dealing with death and dying every day

- Continually seeing illness and suffering

- Seeing younger people so ill

- Losing people you care for over and over

- Seeing the hopelessness, sadness, human trauma, emotions

- Families can be so demanding

- Unrealistic expectations of patients and families

- Patients and families disagree amongst themselves about what should be done

- So much aggressive treatment and no acknowledgement of dying

- Never enough time to do what needs to be done

- No time to spend talking with patients

- Doctors not talking honestly with patients/families

- Work spills over into home life

- Little time or opportunity for closure

- Not being able to give quality care to patients or family 
I just felt like I was being... they were doing something to pamper us a little bit. So they were giving back to us instead of constantly taking and draining us dry. (2)

\section{Benefits in the retreat day}

Four overall themes emerged from the interview data about the retreat program. The first theme focused on the idea that a good time was had by all. Looking back on the day, these interviewees remember a sense of being pampered and being cared for. The homelike setting of the Wellspring location, the food, the relaxation exercises, and the notion it was happening on a "work" day contributed to these feelings.

It was like a fun-day, almost... fun, relaxing, free food, a nap, talk - and we all love to talk - and exercising. It was a really good day. It seemed like, "Oh, is it over? Oh, do we have to go?" you know. And usually you can't wait to get out of here, right? So I think it was really a positive thing. I think they are on to something here... they didn't make it feel like it was an educational day at all. (3)

The second theme focused on the value of connection. The nurses spoke about the opportunity to talk with other cancer nurses about what was happening to them in their daily practice lives and their personal responses to those events. They recognized similarities in the events and in their responses that they had not necessarily been aware of before sharing at the retreat. Mixing the inpatient and outpatient staff served to heighten the sense of surprise that they were experiencing similar stresses. It helped to build bridges in their perception of being a team of nurses in the cancer program.

...it was a connecting experience more than a learning experience. Just being able to listen to each other talk. We all have so many different experiences. (8)

...the one thing that was nice was that everybody was feeling the same types of things. You know, like you always think it's only you who feels this way, but it's most of us. (3)

The notion of being together and talking about the events and emotional responses with one another was seen as something that did not happen in the usual course of the day, especially among nurses from different units. To be able to engage in the conversation in the atmosphere of the retreat allowed the nurses to move beyond merely complaining about the stresses. They were able to talk about their emotional, and sometimes very personal, reactions safely. Realizing that others had similar responses and feelings helped to create a sense of connection. Suddenly the nurses felt they were not so alone in dealing with the events in their daily work lives.

You know, you sometimes think you are so isolated. That's the part that really made an impact on me. Just being able to share the impact of our work on us emotionally. And I guess to gripe about things that bothered us, you know... you don't get a chance to [here on the unit]. But I mean to get to go out and that and talk with nurses from other units, you realize that it is not just you. (19)

The third theme reflected what the nurses felt they had gained from the retreat, the value of support. The opportunity to be together and to share with one another opened a door to feeling supported by one another. The discussions provided opportunity for the nurses to make comments to one another such as, "you handled that well," "I'd have been upset, too," "no wonder you felt frustrated." These types of comments were seen as showing understanding and as validation. Suddenly behaviours they had observed in colleagues made more sense. They began to understand more about why people acted as they did or said what they had said in situations. They began to experience a greater understanding of the challenges they all faced and how the stresses and strains could lead to certain responses and behaviours. And they could begin to express that understanding.
It was a time to express what you were going through. And, certainly, you know, people would talk about it... and you got to know the others... and you can be more understanding of the others whom you work with... it was like we came together as a whole... And the way that we discussed our concerns, it was really like a group therapy. (4)

We had good sharing... a good time and good sharing so we know that we are not alone... We know... we are all really stressed, also. And that is really good. So we know that we are not particularly stressed, but it is kind of like a norm. And I think that is really helpful. (9)

The fourth theme that emerged from these interviews was the value of stories. Storytelling within the group sessions was a powerful tool of connection and of support. Through the telling of stories, nurses were sharing themselves and their perspectives. The process allowed them to find a common ground. The telling of stories in itself is a common human experience, one that is comfortable for many. The context of telling workplace stories with colleagues focused the participants and facilitated learning.

[I liked] the interactions with the other nurses. Finding out about them and how they see themselves as nurses. And just hearing their stories... we appreciate each other more... they shared their dealings with families and patients. Just, I actually felt very good about what they were saying because they had a lot of insight about their patients and themselves. (20)

I think when we shared stories... the stuff that's happened to us, personal stories, allowing us to vent. It was an important part. When we share like that, you build connections with other people in the room... it's bridge building. (5)

\section{Benefits after the retreat day}

The interviewees were asked to describe any significant learning or benefits they experienced following the retreat and whether those benefits had continued for a period of time. They talked about benefits they had realized for themselves and families, in their work life, and in caring for patients and families.

The primary benefits these nurses described were ones for themselves. They felt they had learned a good deal of information at the session, even though the details were vague by the time of the interview. The most lasting learning had been in terms of new relaxation skills and new insights. They had been exposed to new relaxation exercises at the retreat and had been able to use them afterwards.

For me personally, the relaxation techniques, I guess. Using them and coping, things like that... being more aware of a stressful situation... realizing when it is happening to you... when you are affected by it and can make changes. (15)

Well, I use the deep breathing and everything when you get a chance. Always when I go home. Take a deep breath. Yeh. And there are times in here, actually, when you are just having a tough day that you do kind of have to remove yourself from it in order to diffuse things before you explode or do something really stupid. So there are times you have to get away. Just do it. (13)

The information about stress and coping strategies also led some nurses to be more aware of situations that are stressful, why they are stressful, and options for actions to cope with them.

For me, it's the coping that I learned. To cope better and especially coping better with the death and dying. I had a hard time with that. (14)

I would say I make a conscious decision now about choosing to be affected by a situation... the politics and so on. I try maybe to avoid that kind of stress. (15) 
These nurses also gained a better understanding and appreciation for the impact of loss and grief and how that can influence behaviour. This insight helped them have more patience and capacity to see and understand their own and others' experiences. As a result, they felt they were more open, better at listening to others, and ready to acknowledge the reality of stress in their work life.

It is $O K$ to be human, almost to grieve. And if you have a bad day, a bad experience, it is $O K$ to feel that emotion and even express it... I am more aware of that than before. Especially listening to other staff members... more sensitive to them. (16)

One thing it did, it normalized my feelings. I know I am not alone... I am busy and stressed at times, but it is good to hear others say this and communicating the same kind of feeling you share... you realize that for people working in oncology this is the norm... and it's good to realize that. (9)

Some of my co-workers were there that day, and some of the stories, well it made me realize, gave me a different perspective, a respect, a sympathy, just an understanding that, hey my life isn't the only one that hasn't been easy. So maybe, gave me a little more compassion. (11)

The notion of taking time for oneself was also cited as an important insight that stayed with the participants. The retreat served to validate how important it was to make that time. Without time for self, the balance in one's personal life, and the capacity to manage the stresses of one's work life is diminished. Hence, the retreat became a stimulus for some nurses to shift the emphasis of their personal activities.

It was nice to know my feelings are normal... so short-term there was validation of that... long-term, well I suppose the reinforcing of skills about looking after yourself, relaxation skills, life skills. I suppose reinforcing those and you internalize them... that self-care is important before you give care. (18)

How to be good to yourself... resting well, sleeping well, exercises... having a sort of normal social life outside work so you can leave the stresses behind... and the session helped me get into my mind that if I want to have a sense of well-being, being relaxed and work is more stressful... there are things I can do... (17)

Part of the shift some nurses made was to organize more time for their family. Although they felt there was a benefit to them, they also felt it was a benefit to their family to have made this shift.

It really made me think about my family and my time with my daughters. They need me, too. I can't let work take that away. (7)

In terms of work life, nurses felt the retreat had a long-term impact on their appreciation of co-workers and their capacity to support the others. Their added understanding of each other's experiences, and their recognition they were all going through tough times, meant they could be more tolerant. They felt a shared sense of working together, and a comfort in knowing that others were on the same wavelength.

Sometimes in any environment like this, people are at different stages of being overwhelmed... they get to the point they are just keeping their heads above water. They don't have energy for more. Their energy goes to patients and families. There's very little left over for each other... this type of session helps us realize that. (17)

There is comfort in knowing there are nurses all over the hospital in oncology dealing with the same things. Similar experiences, and they are all affected by it differently but similarly. I don't know, it's just nice to know that. (15)
I guess the feeling that I am not by myself with how I feel about nursing oncology patients. And also that I know that I am not by myself. There are other people that feel the same way I do. (14)

With regards to patients and families, nurses had experienced themselves as more empathetic and understanding of their situations and they applied some of their learning about loss and grief to their patients. It allowed them to be more patient, to slow down during interactions with people, and not to be afraid of talking about emotional topics. They realized they were more prepared to ask patients about what might be bothering them and to take the time to listen to the answers.

With patients, families, well, I probably am more attentive listening. I am probably more tuned in and probably I focus, focus more on their experiences at that time in a difficult situation. (16)

I think I am talking to patients more. And getting them to express their feelings and attitudes more and finding out about how they feel instead of just the technical stuff... it creates a better relationship with my patients and a more trusting relationship. I feel I can do more for them once I get to know them better and know what their needs are. (10)

Finally, an overwhelming sense of no longer being alone, not having to shoulder it all by oneself emerged. So often, in the midst of a busy stressful working day, it is easy to just see what needs to be done and what you as an individual must do; it is easy to forget there are others around.

It was more a sense of understanding and camaraderie with everyone else that was there... I came out feeling good about the job that we're doing... it was an ego boost and just that we were doing something useful...I think I have a greater respect for people who are nurses who work here. (13)

You're not, as a nurse, you are not doing oncology nursing by yourself. Your other colleagues feel the same way as you do... sometimes you feel very helpless... other times you ask why? Why is this person stuck with cancer? (14)

\section{Discussion}

The program, Care for the Professional Caregiver, was designed to provide staff nurses with an opportunity to learn more about coping with the stresses of their daily practice as a cancer nurse. It was designed to provide new information, enhance skill development, and enlarge the networks nurses had with other cancer nurses.

The degree of success of the program was both surprising and beyond our expectations. The quantitative and qualitative results provide valuable insight regarding why the program was so successful. They also provide insight regarding what is helpful in supporting cancer nurses who work in the stressful practice environments of today.

The program was designed on the basis of principles of adult learning. Several principles emerged as key in the success of the program: the topics were ones the learners perceived as important and relevant to them, the learners were recognized as having experience and expertise in the topic area, and the learning methods were highly interactive and provided opportunity for immediate practice. Clearly these nurses saw cancer nursing as a stressful experience each day and recognized the value of coping with that stress. The group discussions allowed much opportunity to share stories, tell one another about their practice lives, and learn from each other. Learning relaxation techniques and skills was fun, practical, and active. It should be noted, however, the leaders or facilitators for this learning approach and group work were highly prepared in the field. The leadership is a key ingredient in managing the sessions so the goals are achieved. 
The value of connection with peers and of support gained from sharing stories about similar experiences has been cited by other investigators. In particular, similar benefits have been cited by cancer patients from self-help groups (Gray, Fitch, Davis, \& Phillips, 1997a; Gray, Fitch, Davis, \& Phillips, 1997b). A strong sense of support emerges when people realize they share common experiences, have similar feelings, and lived through the same situations. The sense of isolation and being alone is reduced. Describing these situations to each other, telling the story of what happened, is the way to find and share commonalities. Imbedded in the stories are ideas about how to cope or manage with situations as well as illustrations that can serve to normalize and validate feelings or responses. When a group leader is skilled in using storytelling as a tool for group facilitation, this approach can be powerful.

The findings from this evaluation have implications for managers and administrators regarding strategies to foster quality workplaces for cancer nurses. Staff nurses have identified the importance of support from managers who understand about the pressures in their work lives (Bakker et al., in press). Offering this program and arranging for it to be a paid workday was perceived clearly as support and understanding from the employing organization. The nature of the program, together with the location and food, offered the nurses a sense of being pampered. This was taken as another sign the organization cared about what was happening to its nursing staff. The program content and its agenda offered avenues for attendees to begin caring for one another in new ways. Respect for one another grew as they listened to stories and learned from one another. This caring fosters a sense of team and a feeling of not being alone in the face of adversity. One feels part of

\section{References}

Bakker, D., Fitch, M.I., Green, E., Butler, L., \& Olson, K. (in press). Oncology nursing: Finding the balance in a changing health care system. Canadian Oncology Nursing Journal.

Cohen, M.Z., \& Sarter, B. (1992). Love and work: Oncology nurses' views of the meaning of their work. Oncology Nursing Forum, 19(10), 1481-6.

Cohen, M.Z., Haberman, M.R., Steeves, R., \& Deatrick, J.A. (1994). Rewards and difficulties of oncology nursing. Oncology Nursing Forum, 21(Suppl. 8), 9-17.

Corner, J. (2002). Nurses' experiences with cancer. European Journal of Cancer Care, 11, 193-199.

Feldstein, M.A., \& Gemma, P.B. (1995). Oncology nurses and chronic compounded grief. Cancer Nursing, 18(3), 228-236.

Fitch, M., \& Steele, R. (2003). Supportive care needs of cancer patients: Looking beyond the obvious. Supportive Care in Cancer, 11(6), 423.

Gray, R., Fitch, M., Davis, C., \& Phillips, C. (1997a). Interviews with men with prostate cancer about their self-help group experiences. Journal of Palliative Care, 13(1), 15-21.

Gray, R., Fitch, M., Davis, C., \& Phillips, C. (1997b). A qualitative study of breast cancer self-help groups. Psycho-oncology, 6, 279289.

King, P., \& Jordan-Welch, M. (2003). Nurse-assisted suicide: Not an answer in end-of-life care. Issues on Mental Health Nursing, 24(1), 45-57.

Kushnir, T., Rabin, S., \& Azulai, S. (1997). A discipline study of stress management in a group of pediatric oncology nurses. Cancer Nursing, 10(6), 414-421.

Lamkin, L., Rosiak, J., Buerhaus, P., Mallory, G., \& Williams, M. (2002). Oncology Nursing Society workforce survey. Part II: Perceptions of the nursing workforce environment and adequacy of nurse staffing in outpatient and inpatient oncology settings. Oncology Nursing Forum, 29(1), 93-100. the community of oncology nurses who make a difference to people living with cancer. Attendees gained insight regarding the nature of stress in the workplace and how they might better deal with or manage the reality they face each day.

There are limitations with this study. Given the program was offered to nurses in one cancer program, the data are from nurses who work in that one centre. Additionally, the majority of the nurses who provided evaluative feedback were in oncology more than five years. This is a realistic reflection of the staff at one centre, but their comments may not reflect the opinions of those who are new to the cancer world. This type of program may not be as helpful to nurses new to oncology.

\section{Implications}

Clearly this Care for the Professional Caregiver program served a useful purpose. In light of the anticipated future in cancer care and the ongoing pressures within the work environment, a program such as the one described here should be offered on a regular basis. Cancer nursing is a stressful specialty and helping staff nurses to cope with that stress is important. The benefits in our program were seen at an individual as well as a care delivery level. Future research initiatives could determine whether these observations occur when such a program is offered in other cancer programs and settings. Links between attending such a program and reduction in feelings of stress or in rates of absenteeism could also be explored. Finally, forming partnerships with agencies who have expertise in offering such programs may be a useful approach for cancer leaders to provide assistance for their staff.

Lancely, A. (2001). The impact of cancer on health professionals. In T. Corner \& C. Barley (Eds.) Cancer Nursing - Care in Context. Oxford: Blackwell Science.

Larson, D. (1992). The challenge of caring in oncology nursing. Oncology Nursing Forum, 19, 857-861.

Lev, E.L. (1994). Issues for the nurse caring for the dying patient. Oncology Nursing: Patient Treatment and Support, 1(1), 1-10.

Lewis, A.E. (1999). Reducing burn-out: Development of an oncology staff bereavement program. Oncology Nursing Forum, 26(6), 1065-1069.

Loney, M. (1998). Death, dying and grief in the face of cancer. In C. Burke (Ed.), Psychosocial dimensions of oncology nursing care. Pittsburgh: Oncology Nursing Press Inc.

Lovern, E. (2001). This shortage needs CPR: Studies at odds on whether there are enough to go around. Modern Healthcare, 31(24), 4-5, 16.

McElroy, A.M. (1982). Burn-out: A review of the literature with application to cancer nursing. Cancer Nursing, 5(3), 211-217.

Newlin, N.J., \& Wellisch, D.K. (1978). The oncology nurse: Life on an emotional roller coaster. Cancer Nursing, 1(6), 447-449.

Saunders, J.M., \& Valente, S.M. (1994). Nurses' grief. Cancer Nursing, 17(4), 318-325.

Silverman, D. (2000). Doing qualitative research: A practical handbook. London: Sage.

Vachon, M.L.S. (1986). Myths and realities in palliative/hospice care (pp. 63-79). Hawthorne, NJ: Hawthorne Press.

Wilkinson, S.M. (1994). Stress in cancer nursing - does it really exist? Journal of Advanced Nursing, 20, 1079-1084.

Yasko, J.M. (1983). Variables which predict burn-out experienced by oncology nurse specialists. Cancer Nursing, 6(2), 109-116. 